\title{
A Disaster Resilient Road: Effects of Fines on Density and Shear Strength of Sands
}

\author{
Md. Shahin 1, ", Md. Mehedi Hasan Khan ${ }^{2}$, Md. Niamul Bari ${ }^{3}$ \\ ${ }^{1}$ Department of Disaster Resilience and Engineering, Patuakhali Science and Technology University, Patuakhali, Bangladesh \\ ${ }^{2}$ Local Government Engineering Department, Dhaka, Bangladesh \\ ${ }^{3}$ Department of Civil Engineering, Rajshahi University of Engineering and Technology, Rajshahi, Bangladesh
}

Email address:

shahin_dre@pstu.ac.bd (Md. Shahin), mehedi307@gmail.com (Md. M. H. Khan), niamulbari@gmail.com (Md. N. Bari)

${ }^{*}$ Corresponding author

\section{To cite this article:}

Md. Shahin, Md. Mehedi Hasan Khan, Md. Niamul Bari. A Disaster Resilient Road: Effects of Fines on Density and Shear Strength of Sands. International Journal of Transportation Engineering and Technology. Vol. 6, No. 2, 2020, pp. 38-43.

doi: $10.11648 /$ j.ijtet.20200602.11

Received: March 2, 2020; Accepted: March 16, 2020; Published: April 23, 2020

\begin{abstract}
During a massive flood or earthquake, the roads are mainly damaged due to the looseness of the subgrades. In recent times for any new constructions of roads and embankments the subgrades mainly constructed with the sand filling. It is difficult to achieve the desired degree of compaction beyond a certain limit. That's why the bases (subgrades) become loose. This study aims to overcome the situation by increasing compaction and shear strength properties of sand filling. In this paper, an intensive laboratory investigation of fines with sands is investigated by a series of the proctor test and direct shear test. In this study, fines were mixed with the sand samples in a proportion of $10 \%, 20 \%, 30 \%, 45 \%$ and $55 \%$ to examine the effect on maximum dry density. Tests indicated that 45 to $55 \%$ fines with sands having different Fineness Modulus (FM), the Maximum Dry Density (MDD) of the sand can be increased up to 18 to $26 \%$ depending on FM. The results revealed that the density and shear strength (cohesion) of sand both increase significantly with the addition of fines with it up to a certain percentage. This increment in MDD and shear strength makes the bases (subgrades) stronger and stable. This result can be used in disaster resilient road or embankment construction and also for the structures having a shallow foundation.
\end{abstract}

Keywords: Dry Density, Disaster Resilient Road, Fineness Modulus, Fines with Sands, Shear Strength

\section{Introduction}

Bangladesh has frequently been affected by the storm surge and flood that directly disturb the soil strength in subgrade and basecourse of roads and highways. Saturation of subgrade soil brings its weakest condition being damaged by moving vehicles. As a construction material, the soil has been used since antiquity with both success and failure. The widespread availability and relative economy of earth material make it attractive for use in foundations, embankments, and backfill.

It has long been recognized, first empirically and then scientifically, that compaction improves the physical and mechanical properties of soils in some cases tremendously. Compaction, the expulsion of air volume, generally increases the density of soils thus shear strength, decreases its compressibility, and permeability. Construction like earth fill dam, roadways and embankments really apply compaction effort for construction. Satisfactorily compacted soil has limited permeability to be saturated from flood and storm water.

Matsumura and Tatsuoka [1] studied the effect of compaction conditions and fines content on cyclic undrained strength of saturated soils. They found that cyclic undrained strength decreases with an increase in degree of saturation with respect to optimum saturation. Maximum dry density and unconfined compressive strength increase with the increase in compaction energy and optimum moisture content decreases [2-4]. Compaction with a certain amount of fines content $(30 \%)$ increases the maximum dray density and decrease optimum moisture content [5]. The amalgamate of fines up to a certain percentage increases the maximum dry density of poorly graded sands [6-8]. Dust shield polymer 
increases dry density and shear strength of soils [9].

Fines have also been found to affect the liquefaction potential, compressional characteristics and stress-strain behaviour of soil [10]. Fines content increases the liquefaction resistance of sand [11-14]. Liquefaction resistance increases with the increase in fines content $\left(f_{c}\right)$ up to a threshold of $f_{c}$ and it decreases beyond the threshold [1517]. The increase in the plasticity index of fines content decreases the resistance to the liquefaction [18].

Few recent studies are found to investigate the physical and mechanical properties of sand with fines. The fines content improves dry density, shear strength, and reduce angle of internal friction $(\phi)$ up to a threshold of fines content $[14,19,20]$. The internal friction angle decreases with increase in fine content and cohesion increases [6, 19, 21, 22]. The undrained shear strength, soil modulus, and pore pressure decreased when the clay content increased [23]. Variation of the gradation of the host sand has little effect on the monotonic undrained behaviour where fines content governs the strength [11]. The increment in fine content decrease the critical state friction [24]. Regarding instability, sand with a small amount of $f_{c}(10 \%)$ shows a similar trend like clean sand [25]. The mixture of sand and fines improves the geotechnical properties of soil [26].

Most of the past studies were concentrated on the effect of compaction energies on the dry density and moisture content of soils. Also, liquefaction behaviour of sand with fines had been studied, rigorously. It seems important, for practical purposes, to know the effects of fines content on the dry density, shear strength, and necessary water content for a minimum compacting effort. Comprehensive studies on the effect of fines content on maximum dry density, optimum moisture content and shear strength of sandy soils appeared to be very limited from the viewpoint of disaster resilient road construction. With this view, the present study is concentrating on the investigating of some physical properties, density, and shear strength characteristics of sandy soil with fines content.

\section{Methodology}

\subsection{Sample Collection}

Four types of sand were collected from different places of Barguna and Patuakhali districts in June 2016 have been used for this research work. These sands are different for their various Fineness Modulus (FM) and Fines content. The USCS definition of the sand was used. The sand particles pass through the No.4 sieve and retained on the No. 200 sieve. The particles pass No. 200 sieve was defined as the fines for this study. The fines was not classified whether it was silt or clay.

\subsection{Specimens Preparation}

The collected sand samples were selected as the mother sample for the modification with fines content. Fines was mixed with the sands uniformly to prepare the sample. There was no variation in the types of fines content which means identical fines was used for this study. Liquid limit, plastic limit and plasticity index were 32, 25 and 7, respectively, of the fines content.

\subsection{Testing Procedure}

Standard proctor test and Direct shear test were applied for this investigation. This study used the standard procedure of the proctor test and direct shear test. The proctor test was to explore optimum moisture content (OMC), maximum dry density (MDD). The direct shear test was to determine the shear strength properties of modified sand with fines. Cohesion (c) and angle of friction $(\varphi)$ were calculated from the graph.

The direct shear test was carried out on a soil sample confined in a metal box of square cross-section which is split horizontally at mid-height. A small clearance is maintained between the two halves of the box. The soil is sheared along a predetermined plane by moving the top half of the box relative to the bottom half. The box is usually square in the plan of size $60 \mathrm{~mm} \times 60 \mathrm{~mm}$. Bulk density, $\gamma_{b}$ in $\mathrm{g} / \mathrm{cm}^{3}$ of each compacted specimen was estimated using (1). Equation 2 estimates the dry density, $\gamma_{d}$, in $\mathrm{g} / \mathrm{cm}^{3}$.

$$
\begin{gathered}
\gamma_{\mathrm{b}}=\frac{\mathrm{W}_{2}-\mathrm{W}_{1}}{\mathrm{v}_{\mathrm{m}}} \\
\gamma_{d}=100 * \frac{\gamma_{b}}{100+w}
\end{gathered}
$$

Where,

$\gamma_{b}$ : bulk density in $\mathrm{gm} / \mathrm{cm}^{3}$

$W_{1}$ : weight of [mould + base plate] in $\mathrm{gm}$;

$W_{2}$ : weight of [mold + base plate + soil $]$ in $\mathrm{gm}$;

$v_{m}$ : volume of mold $1000 \mathrm{~cm}^{3}$;

$w$ : mosture content, $\%$;

The dry densities, $\gamma_{d}$, obtained in a series of determinations was plotted against the corresponding moisture content ' $w$ '. A curve was then drawn through the resulting points and the position of the maximum on this curve is determined, which is called maximum dry density (MDD). And the corresponding moisture content is called optimum moisture content (OMC).

\section{Empirical Analysis}

The proposed investigation focused on the incremental change in dry density and shear strength with the increase in fines content for modified sand with fines. Fines of different percentages were mixed with the sands of different Fineness Modulus (FM) to examine the density and shear strength characteristics. These sands were different for their various Fineness Modulus (FM) and fines content, Table 1.

Table 1. Types of collected samples based on the FM and fines content.

\begin{tabular}{lll}
\hline Sample Types & Fineness Modulus (FM) & Initial Fines Content (\%) \\
\hline 1 & 0.21 & 10.37 \\
2 & 0.42 & 12.20 \\
3 & 0.90 & 1.10 \\
4 & 1.44 & 1.00 \\
\hline
\end{tabular}




\subsection{Effects of Fines on Compaction}

The maximum dry density rises until a certain percentage increment of fines content as shown in Figure 1, Figure 2, Figure 3, Figure 4, and Figure 5. After that, dry density decreases. For the sand having $\mathrm{FM}=0.21$, it decreases smoothly but dry density falls sharply for $\mathrm{FM}=0.42$. The sand having FM was 1.44 , whose dry density goes up $55 \%$ fines content, Figure 4. The higher fineness modulus can absorb higher fines content to raise the dry density.

The sand with $\mathrm{FM}=1.44$ shows highest dry density among four types of field samples. But in all cases, the compaction increases with the fines content compared with clean sand. It is not inferable that the increasing trend of FM can confirm higher fines content to be mixed up for better compaction from this study (it requires more tests). It was found that the density of the sand with $\mathrm{FM}=0.21$ can be increased maximum $25.43 \%, 23.22 \%$ for $\mathrm{FM}=0.42$ and $22.18 \%$ for $\mathrm{FM}=0.90$ at $45 \%$ fines content mixed with the sand. The MDD was improved by approximately $22 \%$ for $F M=0.90$ and $17.86 \%$ for $\mathrm{FM}=1.44$ at a certain percentage of fines mixture.

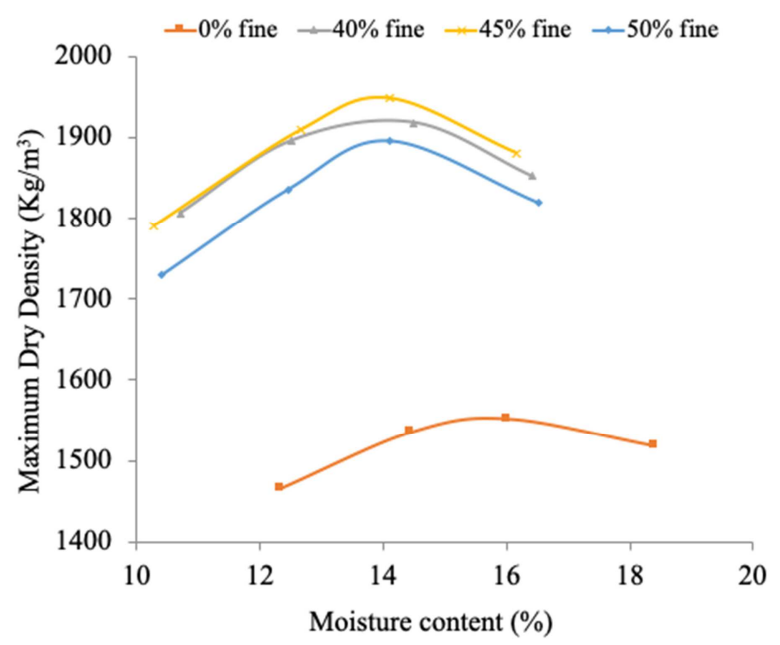

Figure 1. $\left[\gamma_{d}-w\right]$ curve for sand $(F M=0.21)$ with fines.

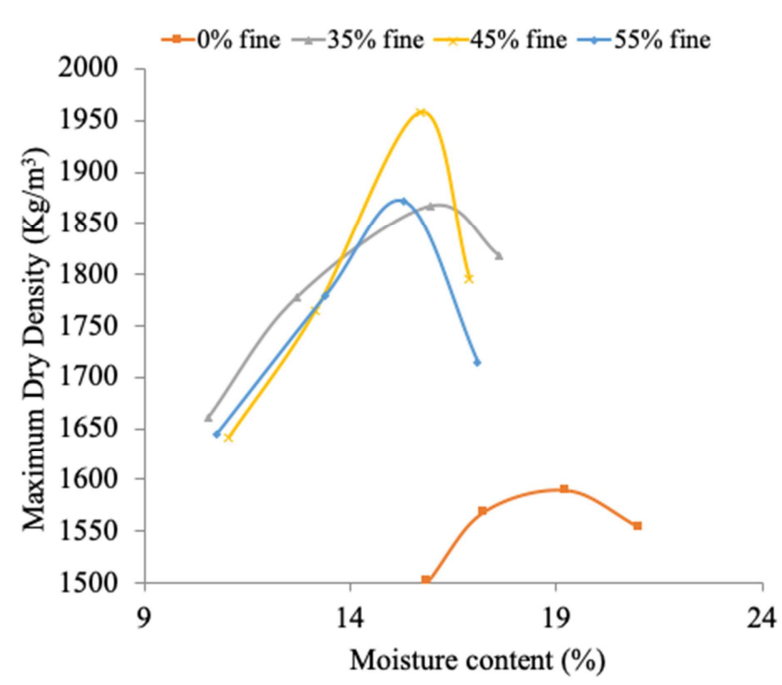

Figure 2. $\left[\gamma_{d}-w\right]$ curve for sand (FM=0.42) with fines.

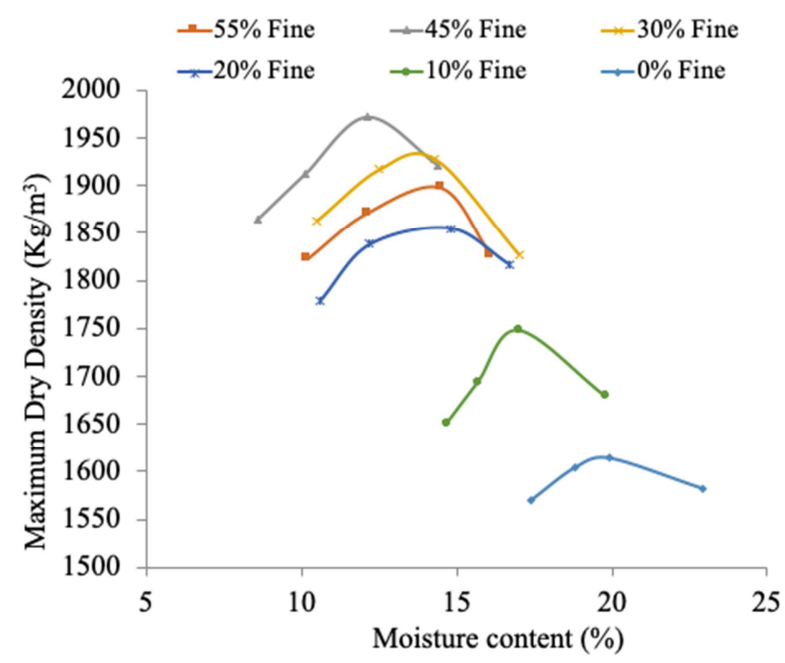

Figure 3. $\left[\gamma_{d}-w\right]$ curve for sand (FM=0.90) with fines.

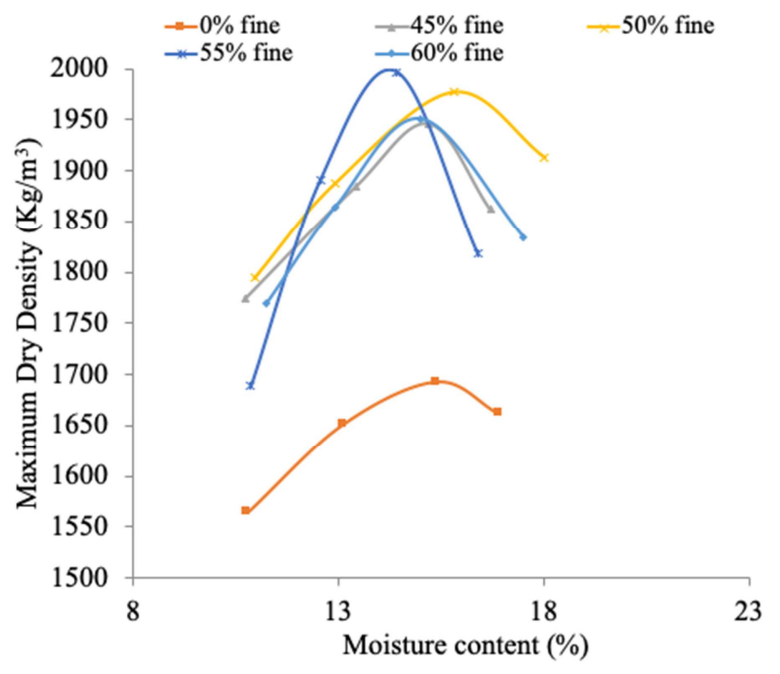

Figure 4. $\left[\gamma_{d}-w\right]$ curve for sand (FM=1.44) with fines.

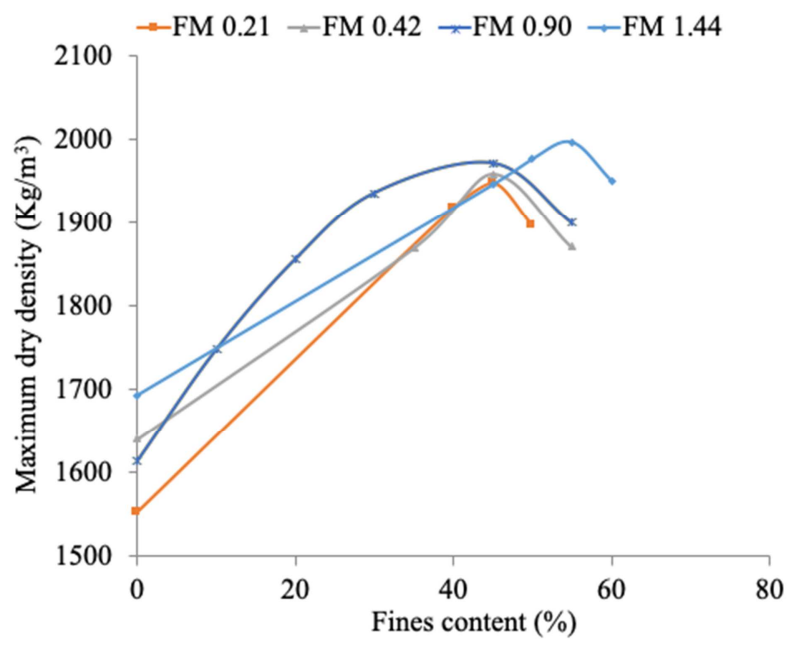

Figure 5. Maximum dry density vs fines content curve.

\subsection{Effects of Fines Content on Shear Strength}

The compaction of the samples was much higher than the sand having no fines content. It was expected to have a 
similar trend in shear strength of the sand with fines. Therefore, the authors selected sand with $\mathrm{FM}=0.42$ and $\mathrm{FM}=1.44$ for further investigation to confirm shear strength characteristics. Shear strength was determined by unconsolidated and undrained (UU) direct shear test. The test results are shown in Figure 6, Figure 7, and Figure 8. The angle of friction decreases with the agglomeration of fines content, Figure 6, but the cohesion upturns. Friction shows an inverse relationship with fines content where cohesion presents positive uptrend as shown in Figure 7. Islam, Badhon and Abedin (2016) found a similar result in their investigation.

The shear strength shows similar trend like dry density with augmentation of fines content. Shear strength falls after a certain percentage of fines content, i.e. $45 \%$ for $\mathrm{FM}=0.42$ and $55 \%$ for $\mathrm{FM}=1.44$. It is consequently inferable that maximum dry density and shear strength showed a very similar trend with the increase of fines content. The higher the compaction, the higher the shear strength.

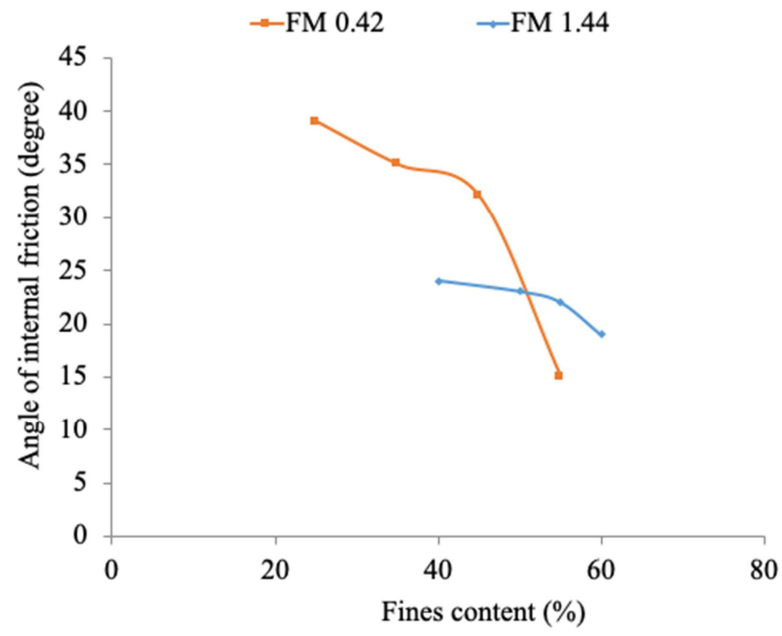

Figure 6. Variation of friction angle vs fines content.

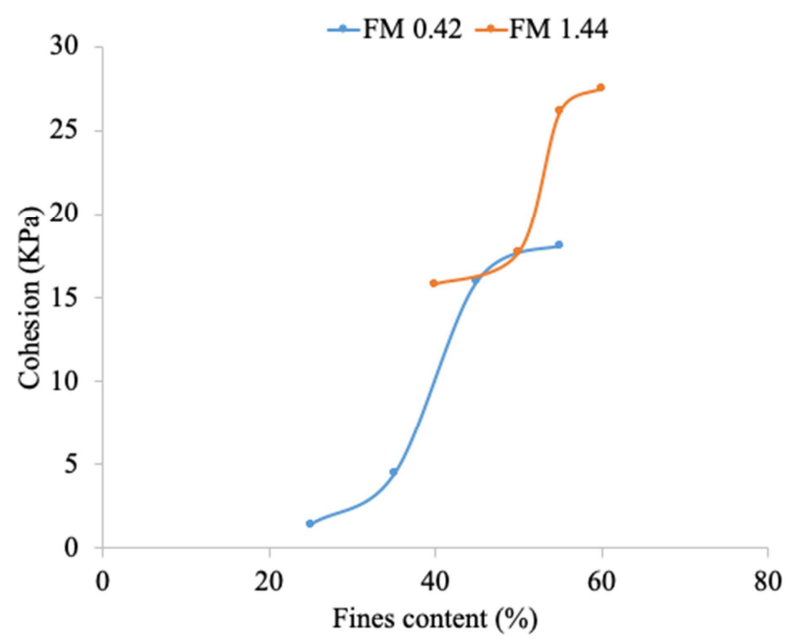

Figure 7. Variation of cohesion vs fines content.

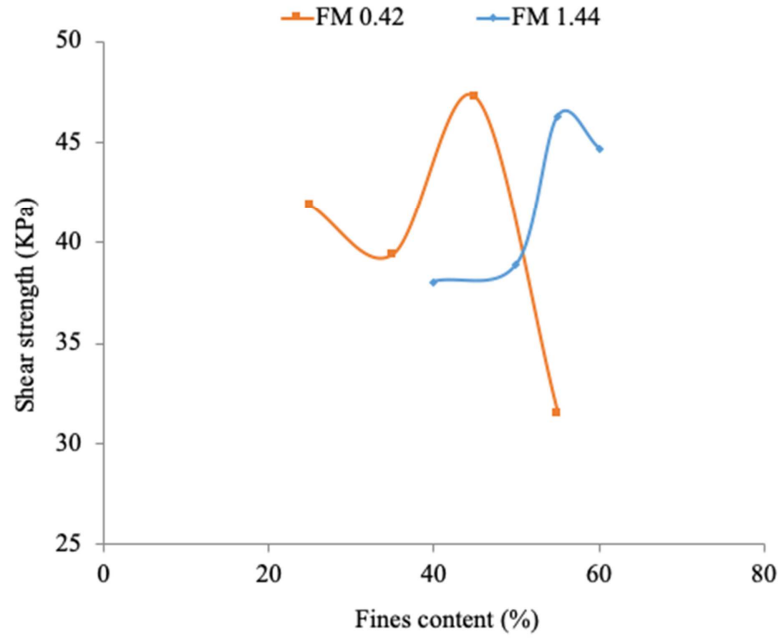

Figure 8. Change in shear strength vs fines content.

During heavy flood or earthquake, the roads are mainly damaged due to the looseness of the subgrades. In recent times for any new constructions of roads and embankments, the subgrade (base) is generally constructed with the sand filling. The compaction of sand is something difficult and the degree of compaction cannot be achieved beyond a certain limit. That's why the bases (subgrade) of the roads or embankments become loose. Storm surge, flood, and earthquake cause weakest road subgrade. The increased density and shear strength of the subgrades reduce the damage of roads or embankments or shallow foundation structures can be reduced up to a certain degree.

To be used effectively, compaction must be tailored to the soil type, moisture condition, and subsequent environment of the compacted product. Thus, the ability of the engineer to identify the soil type accurately takes on prime importance. Wasted effort, such as that in attempting to compact clean sand with sheep-foot-rollers, can result from inattention to the recognition of soil type. The fallacy of making twice as many passes of the roller in an attempt to compensate for overly thick layers or overly wet soil can be avoided by an understanding of the compaction process. An important characteristic of cohesive soils is the fact that compaction improves its engineering properties of shear strength and compressibility.

From the results of this experiment, it is found that the density and shear strength of sand both increases significantly with the addition of fines with it up to a certain percentage. This increment obviously makes the bases (subgrade) stronger and more stable. So, this result can be used very effectively in any road or embankment construction projects and also for the structures having a shallow foundation.

\section{Conclusion}

The effect of fines on the compaction and shear strength is presented. Fines were added up to 55 percent by dry weight 
of sand for compaction and $60 \%$ for the shear strength test. The maximum dry density (MDD) of sand with fines increases with the increment of fines. The angle of friction continues to decrease with the increase of fine content but cohesion increase. Tests resulted that 45 to $55 \%$ fines with sands having different Fineness Modulus (FM), the Maximum Dry Density (MDD) of the sand can be increased up to 18 to $26 \%$ depending on FM. The results revealed that the density and shear strength (cohesion) of sand both increase significantly with the addition of fines with it up to $55 \%$. This increment in MDD and shear strength obviously makes the bases (subgrades) stronger and more stable.

This result can be used in disaster resilient road or embankment construction and also for the structures having a shallow foundation. The finding could be valuable for road construction in the disastrous region of Bangladesh. The fines content will increase the longevity of subgrades and basecourse by rising shear strength and density.

\section{Acknowledgements}

Authors are highly thankful to the Local Government Engineering Department (LGED) for facilitating laboratory investigations.

\section{References}

[1] S. Matsumura and F. Tatsuoka, 'Effect of compaction conditions and fines content on cyclic undrained strength of saturated soils', Soil Dyn. Earthq. Eng., vol. 112, no. 2018, pp. 152-161, Sep. 2018.

[2] S. Hussain, 'Effect of Compaction Energy on Engineering Properties of Expansive Soil', Civ. Eng. J., vol. 3, no. 8, p. 610, Sep. 2017.

[3] S. A. N. M. Yusoff, I. Bakar, D. C. Wijeyesekera, A. Zainorabidin, M. Azmi, and H. Ramli, 'The effects of different compaction energy on geotechnical properties of kaolin and laterite', in AIP Conference Proceedings, 2017, vol. 1875, p. 030009 .

[4] S. A. A. Al-khafaji, 'Effect of the Different Energy of Compaction on Subbse Course of Roads', Saudi J. Eng. Technol., vol. 1, no. 3, pp. 86-91, 2016.

[5] P. K. Kolay and N. Wadiah, 'Effect of Sand Content on Compaction Characteristics of Fine-grained Soil', in National Civil Engineering Conference (NACEC) (NACEC), 2005, vol. 4, no. 1 , pp. 718-725.

[6] V. T.-A. Phan, D.-H. Hsiao, and P. T.-L. Nguyen, 'Effects of Fines Contents on Engineering Properties of Sand-Fines Mixtures', Procedia Eng., vol. 142, pp. 213-220, 2016.

[7] K. Deb, V. Sawant, and A. Kiran, 'Effects of fines on compaction characteristics of poorly graded sands', Int. J. Geotech. Eng., vol. 4, no. 2, pp. 299-304, Apr. 2010.

[8] R. Ahmed, A. Nafees, U. T. Hafiz, and H. F. Sher, 'EFFECT OF FINE ON COMPACTION CHARACTERISTICS OF SANDY SOILS', Civil Engineering Department,The University of Lahore, Pakistan, 2014.
[9] T. A. Ahmed and A. O. Kamel, 'Improvement of Swelling Soil under Traffic Areas Using Dust Shield Polymer', J. Eng. Innov. Technol., vol. 3, no. 2, pp. 368-371, 2013.

[10] V. N. Georgiannou and J. B. Burland, 'The undrained behaviour of clayey sands in triaxial compression and extension', Geotechnique, vol. 40, no. 3, pp. 431-449, 1990.

[11] T. D. Pitman, P. K. Robertson, and D. C. Sego, 'Influence of fines on the collapse of loose sands', Can. Geotech. J., vol. 31, no. 5, pp. 728-739, Oct. 1994.

[12] F. Amini and G. Z. Qi, 'Liquefaction Testing of Stratified Silty Sands', J. Geotech. Geoenvironmental Eng., vol. 126, no. 3, pp. 208-217, Mar. 2000.

[13] P.-H. Tsai, D.-H. Lee, G. T.-C. Kung, and C.-H. Hsu, 'Effect of content and plasticity of fines on liquefaction behaviour of soils', Q. J. Eng. Geol. Hydrogeol., vol. 43, no. 1, pp. 95-106, Feb. 2010.

[14] K. A. Kwa and D. W. Airey, 'Effects of fines on liquefaction behaviour in well-graded materials', Can. Geotech. J., vol. 54, no. 10, pp. 1460-1471, Oct. 2017.

[15] S. Thevanayagam, 'Effect of Fines and Confining Stress on Undrained Shear Strength of Silty Sands', J. Geotech. Geoenvironmental Eng., vol. 125, no. 11, pp. 1024-1027, Nov. 1999.

[16] S. Zlatovic and K. Ishihara, 'On the influence of nonplastic fines on residual strength.', in 1st Internationa Conference on Earthquake Geotechical Engrgineering, K. Ishihara, ed., A.A. Balkema, Rotterdam, The Netherlands, 239, 1995.

[17] V. C. Xenaki and G. A. Athanasopoulos, 'Liquefaction resistance of sand-silt mixtures: an experimental investigation of the effect of fines', Soil Dyn. Earthq. Eng., vol. 23, no. 2003, pp. 183-195, Apr. 2003.

[18] S.-S. Park and Y.-S. Kim, 'Liquefaction Resistance of Sands Containing Plastic Fines with Different Plasticity', J. Geotech. Geoenvironmental Eng., vol. 139, no. 5, pp. 825-830, May 2013.

[19] E. Balaban, A. Smejda, and M. I. Onur, 'An Experimental Study on Shear Strength Behavior of Soils Under Low Confining Pressure', in Proceedings of the 4th World Congress on Civil, Structural, and Environmental Engineering, 2019, pp. 1-8.

[20] M. A. Islam, F. F. Badhon, and M. Z. Abedin, 'Effect of fine content on shear strength of sand', in Proceedings of 3rd International Conference on Advances in Civil Engineering, 21-23 December 2016, CUET, Chittagong, Bangladesh Islam, Imam, Ali, Hoque, Rahman and Haque (eds.), 2016, no. February 2017, pp. 191-196.

[21] T. ISLAM, 'Effect of Fine Content on shear strength characteristics of sandy soil', 2017.

[22] K. J. Osinubi, A. O. Eberemu, A. O. Bello, and A. Adzegah, 'Effect of Fines Content on the Engineering Properties of Reconstituted Lateritic Soils in Waste Containment Application', Niger. J. Technol., vol. 31, no. 3, pp. 277-287, 2012.

[23] T. S. Y and L. C. Y, 'Undrained response of mining sand and fines contents', J. Civ. Struct. Eng., vol. 1, no. 4, pp. 844-51, 2011. 
[24] D. Kim, M. Sagong, and Y. Lee, 'Effects of fine aggregate content on the mechanical properties of the compacted decomposed granitic soils', Constr. Build. Mater., vol. 19, no. 3, pp. 189-196, Apr. 2005.

[25] J. Chu and W. K. Leong, 'Effect of fines on instability behaviour of loose sand', Géotechnique, vol. 52, no. 10, pp. 751-755, Dec. 2002.
[26] S. C. Sebastian and P. K. C., 'Variation in Coefficient of Consolidation and Modulus of Elasticity Values of Clayey Soil Randomly R', Int. J. Sci. Technoledge, vol. 3, no. 10, pp. 68-72, 2015. 